International Journal of Instruction e-ISSN: 1308-1470 • www.e-iji.net

\title{
EFL Teachers' Learning and Teaching Beliefs: Does Critical Thinking Make a Difference?
}

Mehdi Dehghayedi

$\mathrm{PhD}$ candidate, Department of English Language Teaching, Islamic Azad University, Shiraz, Iran,m.dehghayedi@yahoo.com

\section{Mohammad Sadegh Bagheri}

Asst. Prof., corresponding author, Department of English Language Teaching, Islamic Azad University, Shiraz, Iran, bagheries@ gmail.com

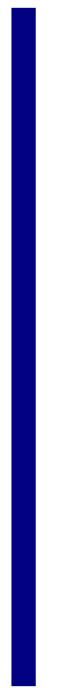

Current research in the field of language education is more concerned with motives underlying successful practicing teachers' behaviours rather than techniques and methods for effective teaching. It is now recognized that there are only good teachers, there is not such a thing as good as teaching. This correlational study is therefore designed and conducted to reveal how well teachers' critical thinking as well as its subcomponents can predict EFL teachers' language learning beliefs and their respective levels. Accordingly, two respective questionnaires, Watson-Glaser Critical Thinking Appraisal and Beliefs about Language Learning Inventory, were given to $130 \mathrm{EFL}$ teachers conveniently sampled, and the elicited data were analyzed via correlational and multiple/multivariate regression analyses. The results indicated that 24 percent of the variance in learning beliefs was explained by the five levels of critical thinking. The collective contribution of the five levels of critical thinking were only significant to three of the five dependent levels, i.e. $9 \%$ to language nature, $26 \%$ to motivation and expectation, and $25 \%$ to learning and communication. Also, only the contribution of assumption level was significant just to learning/communication. What can be inferred from the findings is that foreign language teachers' learning and teaching beliefs can be, to a large extent, predicted from their levels of criticality.

Keywords: EFL teachers, critical thinking, learning and teaching beliefs, regression analysis, language education

\section{INTRODUCTION}

Critical thinking (CT) has been interpreted in a number of different ways. There seems to be little agreement on exactly what critical thinking is (Allen, Rubenfeild, Scheffer, 2004, as cited in Fahim \& Ahmadi, 2012). Its most significant feature is that it does not take anything as a blind faith. From the time of Socrates up to now, concerns about the need for an educated citizenry and quality work-force, the ability to think critically and

Citation: Dehghayedi, M., \& Bagheri, M. S. (2018). EFL Teachers' Learning and Teaching Beliefs: Does Critical Thinking Make a Difference? International Journal of Instruction, 11(4), 223-240. https://doi.org/10.12973/iji.2018.11415a 
to reason well has been regarded as an integral and necessary outcome of education (Reed, 1998). For language teachers to act autonomously, high levels of criticality are needed.

A variety of definitions of critical thinking has been provided by theorists and educators. Chafee (1985, as cited in Klimoviene, Urboneine \& Barzdziukiene, 2006) says that critical thinking is "making sense of our world by carefully examining our thinking and the thinking of others in order to clarify and improve our understanding". Siegel (1988, as cited in Liaw, Huang, \& Chen, 2007) defines critical thinking as "the educational cognate of rationality" (p. 32). Schafersman (1998) calls critical thinking as logical, analytical, reasonable, higher order, reflective, and, scientific thinking as well as reasoning skills.

According to Chance (1986, p. 6) critical thinking is the ability to analyze facts, generate and organize ideas, defend opinions, make comparisons, draw inferences, evaluate arguments and solve problems. Mayer and Goodchild (1990, p. 4) describe critical thinking as an active, systematic process of understanding and evaluating arguments. Scriven and Paul (2012) take it as the intellectually disciplined process of actively and skilfully conceptualizing, applying, analyzing, synthesizing, and/ or evaluating information gathered from, or generated by observation, experience, reflection, reasoning, or communication as guide to belief and action. According to Elder and Paul (1997) "critical thinking is best understood as the ability of thinkers to take charge of their own thinking. This requires that they develop sound criteria and standards for analyzing and assessing their own thinking and routinely use those criteria and standards to improve its quality". Ennis (1989) calls it as a reasonable, reflective thinking that is focused on deciding what to believe and do. Facione (2000) categorizes critical thinking in six cognitive skills: interpretation, analysis, evaluation, inference, explanation, and self-regulation.

Lipman (1988, as cited in Iakovos, 2011) argues that there is a distinction between ordinary thinking and critical thinking. Ordinary thinking is simple, straightforward and without standards. On the contrary, critical thinking is more complex and is on the basis of standards of objectivity, utility, or consistency. He advocates the idea that critical thinking does not contain only the mental processes which people employ to solve problems or to make decisions, but it includes "skillful, responsible thinking that facilitates good judgment since it relies on criteria, is self-correcting, and is sensitive to context". Language education in Iran as an EFL situation has been based on a traditional transmission mode of language teaching in which teachers' creativity and autonomy for deciding what needs be done inside the class have been diminished; therefore, the importance of critical thinking should be more treated in current language teaching and learning research.

\section{Teachers' Beliefs}

Teachers' beliefs, practices and attitudes are important for understanding and improving educational processes. They are closely linked to teachers' strategies for coping with challenges in their daily professional life and to their general well-being, and they shape 
students' learning environment and influence student motivation and achievement. Furthermore, they can be expected to mediate the effects of job-related policies - such as changes in curricula for teachers' initial education or professional development - on student learning. To put into other words, teachers' professional knowledge and actual practices may differ not only among countries but also among teachers within a country. To gain an understanding of the prevalence of certain beliefs and practices, it is therefore important to examine how they relate to the characteristics of teachers and classrooms. For example, previous research suggests that the beliefs and practices of female and male teachers may systematically differ (e.g. Singer, 1996).

In fact, beliefs about language learning have been considered as an important variable, like many other individual differences in language learning (Dörnyei, 2005; Horwitz, 1999; Wenden, 1999). Beliefs about language learning were defined as "opinions on a variety of issues and controversies related to language learning" (Horwitz, 1987, p. 120). Wenden (1999) considered language-learning beliefs as metacognitive knowledge from a wider perspective, and defined them as "the acquired knowledge about learning: the nature of learning, the learning process, and humans as learners, including themselves" (p. 435). Over the past two decades, many researchers have explored language learning beliefs in various studies, covering varying groups of learners in different settings of learning: foreign language learners and English as foreign or second language (EFL/ESL) learners (Bernat, 2004; Horwitz, 1987, 1988; Kern, 1995; Peacock, 1999; Riley, 2009; Sakui \& Gaies, 1999; Yang, 1999). This situation reflects the potential impact of the beliefs on language learning, and consequently on the outcome of learning (Abraham \& Vann, 1987; Mori, 1999; Tanaka \& Ellis, 2003). Also, Horwitz (1985) categorized beliefs about language learning into the following five themes: (a) foreign language aptitude; (b) the difficulty of language learning; (c) the nature of language learning; (d) learning and communication strategies; and (e) motivation and expectations; these categories were manifested in Horwitz's (1985) Beliefs About Language Learning Inventory (BALLI), which is a major concern in the present study. Therefore, this study intends to determine how well do the five subcomponents of critical thinking, i.e. inference, assumption, deduction, interpretation, and argumentation, predict teachers' language learning beliefs in general, and its subcomponents, i.e. language aptitude, nature of language, motivation and expectation, difficulty of language learning, and learning and communication, in particular. In fact, it is mainly intended to determine to what extent language teachers learning and teaching beliefs can be predicted from their levels of criticality.

\section{LITERATURE REVIEW}

Fahim, Barjesteh, and Vaseghi (2012) assert that the development of critical thinking has become a key goal for educators in first and second language contexts. But it is found that the use of such activities has still not become common in a number of EFL situations. The lack of awareness about how levels of thinking can be conceptualized in English language teaching (ELT) activities is prevalent despite the fact that language learning is related to historical, social, cultural, and political issues. Therefore, a lot of people who are engaged in the process of language learning like lesson planners, 
material developers, teachers, and learners should work on critical thinking. Alan and Stoller (2005, as cited in Talebinejad \& Matou, 2012) state that promoting the foreign language learning, contents, and real-life skills projects "requires a combination of teacher guidance, teacher feedback, student's engagements, and elaborated tasks with some degree of challenge" (p. 11).

According to Vdovina and Gaibisso (2013) critical thinking is related to quality thinking and, if adequately developed, helps learners communicate with others, acquire knowledge, deal with ideas, beliefs, and attitudes more skillfully. Language plays a crucial role in all these areas. According to them learning a foreign language requires more thinking. This is because languages are determined culturally. As the cultures differ, so do languages. Considering the culturally-oriented nature of language learning, educators have recently accentuated the significance of developing higher-order thinking skills in ESL and EFL classrooms (Chamot, 1995; Tarvin \& AlArishi, 1991, as cited in Nosratinia \& Zaker, 2013) and empirical evidence supports the usefulness of teaching critical thinking skills along with English as a second or foreign language (Chapple \& Curtis, 2000; Davidson, 1994, 1995, as cited in Nosratinia \& Zaker, 2013). According to Kabilan (2000), it requires asking learners questions and listening to learners' questions. This is a practice which forces and challenges learners to think creatively and critically to match to critical attitude to the world.

Shirkhani and Fahim (2011) maintain that critical thinking has been used in first language acquisition for a long time and has been recently introduced and received a high position in foreign language teaching (ELT) settings. According to Shirkhani and Fahim (2011), the enhancement of critical thinking into the FLT classroom is very important for some reasons. Firstly, if language learners are responsible for their own thinking, they can monitor and assess their own ways of learning more successfully. Secondly, critical thinking makes learners more experienced in learning and makes the language more meaningful for them. Thirdly, critical thinking is highly correlated with learners' achievement (Rafi, n.d.). The learners may become proficient language users if they are motivated and taught the ways of showing critical thinking in English language usage, which signifies that the learners must be reflective in their production of ideas, and they may critically support those ideas with logical details (Rafi, n.d.). They also state that language learners who have enhanced critical thinking skills are able to do activities which other learners are incapable to do. In a study Mahyuddin, Pihie, Elias, \& Konting (2004) explain that language learners with critical thinking ability are able to think critically and creatively to achieve the goals of the curriculum; they are able to make decisions and solve problems; able to use their thinking skills, and to understand language or its contents; able to treat thinking skills as lifelong learning; and at last intellectually, physically, emotionally and spiritually well-balanced. There are many different factors which influence learners' critical thinking skills. In their study, they examine two of these factors which are materials used and types of activities introduced and worked on in the classroom. Therefore, through managing classroom materials and activities, language teachers can help learners enhance critical thinking skills. All language learners must engage in critical thinking, regardless of their language proficiency level since it is an ongoing process. Critical thinking includes the use of 
information, experience, and world knowledge in ways which let second language learners look for alternatives, make inferences, ask questions, and solve problems, thereby showing understanding in different complex ways (Liaw, 2007).

With respect to teaching beliefs, Lai Yu-Ling (2005) investigated teaching vocabulary learning strategies: awareness, beliefs, and practices in a survey of Taiwanese senior high school teachers. The study was therefore an attempt to find out the correlations between teachers' beliefs and their teaching practices. A questionnaire was implemented to collect data on the issues involved. The results have suggested that the English teachers studied were aware of a range of vocabulary learning strategies, including both direct and indirect approaches to vocabulary acquisition. Some teaching practices, however, seemed not to conform to research-informed orientation, implying the gap between the reality in the language classroom and implications from empirical research. Generally speaking, there existed positive correlations between the teachers' beliefs and their instructional practices.

\section{METHOD}

\section{Participants}

The participants of the study were130 (68 female and 62 male) English teachers who were conveniently sampled from language institutes in Shiraz, Borazjan, and Bushehr cities in Iran. The age range of the participants was between 25 to 39 years old. The teachers who had at least a two-year teaching experience were included in the study. The participants were either BA or MA holders of ELT, English literature, and translation studies.

\section{Instrumentation}

\section{Watson-Glaser Critical Thinking Appraisal (W-GCTA)}

To evaluate teachers' critical thinking ability, the "Watson-Glaser Critical Thinking Appraisal" (CTA) (Online Version) was employed. The Watson-Glaser Critical Thinking Appraisal has a distinguished history. It was developed in 1920s. It measures crucial abilities and skills involved in critical thinking. In organizations, it has been used as a selection and development tool and it has been used in academic contexts as a measure of gains in critical thinking skills. It has been adapted and translated for use in languages other than English. It is a psychometric test of critical thinking and reasoning. The Watson-Glaser Critical Thinking Appraisal (W-GCTA) measures skills related to problem solving and decision making using different question types. Critical thinking is the ability to identify and analyze problems as well as seek and evaluate relevant information in order to reach an appropriate conclusion. According to difficulty and format, the questions are different in order to measure all aspects of critical thinking ability. Watson-Glaser Critical Thinking Appraisal (W-GCTA) is composed of a set of five tests. Each test is related to somewhat different aspect of critical thinking: Inference, Assumption, Deduction, Interpretation and Argumentation. The reliability of the questionnaire calculated through Cronbach alpha was 0.81 which is high. The content Validity of the two scales was confirmed through expert judgment. 


\section{Beliefs about Language Learning Inventory (BALLI)}

As a dependent variable, beliefs about language learning of Iranian EFL teachers in language institutes were elicited using a modified version of a survey entitled, Beliefs About Language Learning Inventory (BALLI), which was published by Horwitz (1987). This Likert-scale questionnaire consists of 43 items. Horwitz (1987) categorized the 43 BALLI items into the following five themes: (a) foreign language aptitude (10 items); (b) the difficulty of language learning (4 items); (c) the nature of language learning (7 items); (d) learning and communication strategies (10 items); and (e) motivation and expectations (12 items). The reliability of the questionnaire calculated through Cronbach alpha was 0.89 which is high.

\section{Data Collection Procedures}

Data collection was carried out through four different questionnaires mentioned in the previous sections. The questionnaires were administered in person. The respondents were also requested to leave comments on the relevance and ambiguity of items at the end of each questionnaire. Prior to the administration of the questionnaires, their content validity was checked through expert judgment. Two PhD holders in English language teaching were requested to determine to what extent the items of the scales adequately measure the respective construct. They both confirmed the construct- relatedness of the items.

\section{Data Analysis Procedures}

In order to analyze the data gathered through the administration of the two questionnaires, the following steps were pursued by the researcher:

1. The numerical data were transferred to SPSS software the $24^{\text {th }}$ version.

2. The reliability of the questionnaires was calculated through Cronbach Alpha presented in the previous sections.

3. Multiple regression was also used to see which variables best predict teacher belief in general in response to the research question of the study.

\section{FINDINGS}

In order to answer the first part of this question, the analysis employed was multiple regression. However, prior to the analysis, it was made sure that the data to be analyzed could actually be analyzed using multiple regression. This was done because it is only appropriate to use multiple regression if the data passes several assumptions that are required for multiple regression to entail a valid result. Accordingly, the normality of distribution in the scores related to all the independent and dependent variables was checked as a prerequisite for checking their correlation. Also, as it was checked formerly, the dependent variable was measured on a continuous scale, i.e. the language learning belief was a continuous variable. Similarly, the five independent variables were also checked in this regard; i.e. all the five variables of inference, assumption, deduction, interpretation, and argumentation abilities were also of a continuous-scale type. Then, the independence of observations, i.e. the independence of residuals, was 
checked using the Durbin-Watson statistic via SPSS which can be observed in the Model Summary table of multiple regression analysis below.

Table 1

Model Summary

\begin{tabular}{cccccc}
\hline Model & $\mathrm{R}$ & R Square & Adjusted R Square & Std. Error of the Estimate & Durbin-Watson \\
\hline 1 & $.496^{\mathrm{a}}$ & .247 & .216 & 10.45561 & 1.952 \\
\hline
\end{tabular}

a. Predictors: (Constant), Inference, Assumption, Deduction, Interpretation, Argumentation

b. Dependent Variable: Learning Beliefs

As it is shown in Table 1, the Durbin-Watson analysis indicated that $d=1.95$, which was between the two critical values of $1.5<\mathrm{d}<2.5$ (Statistics Solutions, 2017). Therefore, it could be assumed that there was no first order linear auto-correlation in the present multiple linear regression data. Also, the above figures can properly violate the multicollinearity assumption. In other words, the scatterplots show that the five independent variables of inference, assumption, deduction, interpretation, and argumentation abilities show some relationships with the dependent variable of language learning beliefs. Table 30 summarizes all the respective correlational coefficients which were previously indicated above one by one.

Table 2

Summary of correlations

\begin{tabular}{|c|c|c|c|c|c|c|c|}
\hline & & Belief & Inference & Assumption & Deduction & Interpretation & Argumen \\
\hline \multirow{3}{*}{ Belief } & Pearson Correlation & 1 & $-.443^{* *}$ & $-.409^{* *}$ & $.379^{* *}$ & $-.394^{* *}$ & $-.310^{* *}$ \\
\hline & Sig. (2-tailed) & & .000 & .000 & .000 & .000 & .000 \\
\hline & $\mathrm{N}$ & 130 & 130 & 130 & 130 & 130 & 130 \\
\hline \multirow{3}{*}{ Inference } & Pearson Correlation & $-.443^{* *}$ & 1 & $.634^{* * *}$ & $-.742^{* *}$ & $.557^{* *}$ & $.558^{* *}$ \\
\hline & Sig. (2-tailed) & .000 & & .000 & .000 & .000 & .000 \\
\hline & $\mathrm{N}$ & 130 & 130 & 130 & 130 & 130 & 130 \\
\hline \multirow{3}{*}{ Assumption } & Pearson Correlation & $-.409^{* *}$ & $.634^{* * *}$ & 1 & $-.564^{* *}$ & $.485^{* *}$ & $.287^{* *}$ \\
\hline & Sig. (2-tailed) & .000 & .000 & & .000 & .000 & .001 \\
\hline & $\mathrm{N}$ & 130 & 130 & 130 & 130 & 130 & 130 \\
\hline \multirow{3}{*}{ Deduction } & Pearson Correlation & $.379^{* *}$ & $-.742^{\text {*** }}$ & $-.564^{\text {** }}$ & 1 & $-.547^{* * *}$ & $-.432^{* * *}$ \\
\hline & Sig. (2-tailed) & .000 & .000 & .000 & & .000 & .000 \\
\hline & $\mathrm{N}$ & 130 & 130 & 130 & 130 & 130 & 130 \\
\hline \multirow{3}{*}{ Interpretation } & Pearson Correlation & $-.394^{* *}$ & $.557^{* *}$ & $.485^{* *}$ & $-.547^{* *}$ & 1 & $.603^{* *}$ \\
\hline & Sig. (2-tailed) & .000 & .000 & .000 & .000 & & .000 \\
\hline & $\mathrm{N}$ & 130 & 130 & 130 & 130 & 130 & 130 \\
\hline \multirow{3}{*}{ Argument } & Pearson Correlation & $-.310^{* *}$ & $.558^{* *}$ & $.287^{* *}$ & $-.432^{* *}$ & $.603^{* *}$ & 1 \\
\hline & Sig. (2-tailed) & .000 & .000 & .001 & .000 & .000 & \\
\hline & $\mathrm{N}$ & 130 & 130 & 130 & 130 & 130 & 130 \\
\hline
\end{tabular}

As Table 2 indicates, all the correlational coefficients are meaningful and significant ( $\mathrm{p}$ $<.01)$, and violate multicollinearity $(\mathrm{r}<.7)$ as a presumption for multiple regression analysis (Pallant, 2016). The following scatterplot (Figure 32) show the collective correlation among these variables. In other words, they show that all the variables in this study have a sort of relationship with each other while at the same time with their correlations. Collinearity statistics also confirmed the lack of multicollinearity regarding 
the variables in the present study. In other words, the two values of Tolerance and VIF (Variance Inflation Factor) yielded satisfactory indices. Table 3 shows the extent of these two values.

Table 3

Collinearity Statistics

\begin{tabular}{lllcc}
\hline & \multicolumn{1}{c}{ Model } & Tolerance & VIF \\
\hline \multirow{3}{*}{1} & Inference & .319 & 3.131 \\
\cline { 2 - 4 } & Assumption & .538 & 1.858 \\
\cline { 2 - 4 } & Deduction & .414 & 2.415 \\
\cline { 2 - 4 } & Interpretation & .499 & 2.002 \\
\cline { 2 - 4 } & Argumentation & .538 & 1.860 \\
\hline
\end{tabular}

a. Dependent Variable: Learning Beliefs

Table 3 proves that the five variables in this phase of the present study are not highly correlated due to the appropriate extent of Tolerance and VIF values related to all independent variables; i.e. inference: Tolerance $=.31>.10$, and VIF $=3.13<10$; assumption: Tolerance $=.53>.10$, and VIF $=1.85<10$; deduction: Tolerance $=.41\rangle$ .10 , and $\mathrm{VIF}=2.41<10$; interpretation: Tolerance $=.49>.10$, and $\mathrm{VIF}=2.00<10$; and argumentation: Tolerance $=.53>.10$, and $\mathrm{VIF}=1.86<10$. As it was mentioned before, according to Pallant (2016, p. 159), the "commonly used cut-off points for determining the presence of multicollinearity" include the "tolerance value of less than .10 , or a VIF value of above $10, "$ none of which are present in the current study. Consequently, this issue rejects the presence of multicollinearity in these five independent variables of the present phase.

In addition, the data in the present phase showed homoscedasticity, i.e. the variances along the line of best fit remained similar while moving along the line.

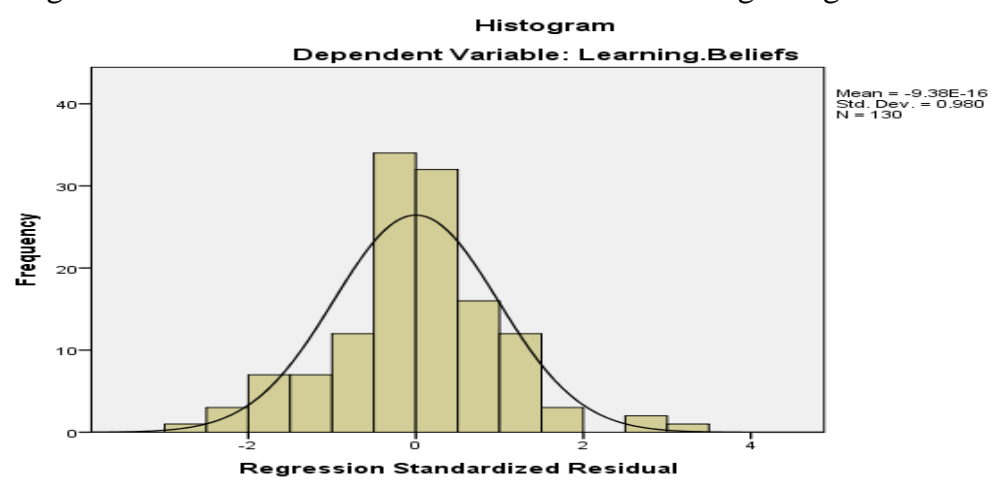

Figure 4

Normality Histogram of Regression Standardized Residual

Finally, as one of the assumptions of conducting multiple regression taken into account in the current research question, Figures 4 can imply some information related to the absence of considerable outliers in the present data. As it was formerly mentioned, Tabachnick and Fidell (2013; also cited in Pallant, 2016, p. 160) define "outliers as 
cases that have a standardized residual of more than 3.3 or less than -3.3 ." Table 4 confirms the concerned issue as follow.

Table 4

Residuals Statistics

\begin{tabular}{lccccr}
\hline Predicted Value & 130.6736 & 155.9756 & 147.3231 & 5.86328 & 130 \\
\hline Residual & -29.13231 & 31.79030 & .00000 & 10.25098 & 130 \\
\hline Std. Predicted Value & -2.840 & 1.476 & .000 & 1.000 & 130 \\
\hline Std. Residual & -2.786 & 3.041 & .000 & .980 & 130 \\
\hline
\end{tabular}

a. Dependent Variable: Learning Beliefs

As it is indicated in Table 4, the maximum and minimum cases of standardized residuals are 3.04 and -2.78 , respectively. In other words, this table shows that all the 130 cases in this study were within the standardized residual value range, i.e. from -3.00 to 3.00 , devoid of any outliers regarding this range, though some within-the-range outliers are clearly observable in the following scatterplot (Figure 35); that is, the standardized residual values could mostly be regarded as close to the standardized predicted values, i.e. between -2.84 and 1.47. Accordingly, ensuring that almost all the multiple regression assumptions were met, this study conducted a standard multiple regression analysis so as to determine how well the five subcomponents of critical thinking, i.e. inference, assumption, deduction, interpretation, and argumentation abilities can predict the dependent variable of language learning beliefs in general. In this vein, Table 5 shows the descriptive statistics of the concerned variables.

Table 5

Descriptive Statistics

\begin{tabular}{lccc}
\hline & Mean & Std. Deviation & $\mathrm{N}$ \\
\hline Learning Beliefs & 147.3231 & 11.80935 & 130 \\
\hline Inference & 1.7010 & 2.90522 & 130 \\
\hline Assumption & 2.7413 & 2.24579 & 130 \\
\hline Deduction & 3.9411 & 4.78035 & 130 \\
\hline Interpretation & 2.1230 & 1.59949 & 130 \\
\hline Argumentation & 3.0516 & 3.96849 & 130 \\
\hline
\end{tabular}

As Table 5 indicates, the mean scores of learning belief, inference, assumption, deduction, interpretation, and argumentation are 147, 1.7, 2.74, 3.94, 2.12, and 3.05, respectively. This shows that the dependent variable enjoys the highest mean score with the standard deviation of 11 , and among the independent variables, deduction and inference have the highest (3.94) and the lowest (1.7) mean scores, respectively. Table 6 shows the model summary of the data.

Table 6

Model Summary

\begin{tabular}{ccccc}
\hline Model & R & R Square & Adjusted R Square & Std. Error of the Estimate \\
\hline 1 & .496 & .247 & .216 & 10.45561 \\
\hline
\end{tabular}

a. Predictors: (Constant), Inference, Assumption, Deduction, Interpretation, and Argumentation

b. Dependent Variable: Learning Beliefs 
As it is shown in Table $6, \mathrm{R}^{2}=.24$. In other words, $\mathrm{R}$ square or the coefficient of multiple determination indicates that 24 percent of the variance in the dependent variable of learning beliefs is explained jointly by the five independent variables of inference, assumption, deduction, interpretation, and argumentation together. Nonetheless, in order to see whether this percentage of contribution is significant or not, the ANOVA table must be observed. Table 7 reveals this issue.

Table 7

ANOVA

\begin{tabular}{llccccc}
\hline \multicolumn{1}{c}{ Model } & Sum of Squares & Df & Mean Square & F & Sig. \\
\hline \multirow{2}{*}{1} & Regression & 4434.775 & 5 & 886.955 & 8.113 & .000 \\
\cline { 2 - 6 } & Residual & 13555.656 & 124 & 109.320 & & \\
\cline { 2 - 6 } & Total & 17990.431 & 129 & & & \\
\hline
\end{tabular}

Dependent Variable: Learning Beliefs

Predictors: (Constant), Inferences, Assumptions, Deductions, Interpretations, Argumentation

As Table 7 shows, the mentioned $\mathrm{R}^{2}$ in the previous table is a significant contribution. In other words, $24 \%$ of teachers' beliefs on language learning is significantly explained by the combination of their inferences, assumptions, deductions, interpretations, argumentation, i.e. $\mathrm{F}(5,124)=8.11, \mathrm{p}<.05$. In order to see each independent variable contribution percentage as well as its respective significance level, Table 8 below must be viewed.

Table 8

Coefficients

\begin{tabular}{|c|c|c|c|c|c|}
\hline \multirow{2}{*}{ Model } & \multicolumn{2}{|c|}{ Unstandardized Coefficients } & \multirow{2}{*}{$\frac{\text { Standardized Coefficients }}{\text { Beta }}$} & \multirow{2}{*}{$\mathrm{T}$} & \multirow{2}{*}{ Sig. } \\
\hline & $\mathrm{B}$ & Std. Error & & & \\
\hline (Constant) & 167.646 & 8.332 & & 20.120 & .000 \\
\hline Inferences & -.813 & .561 & -.200 & -1.451 & .149 \\
\hline Assumptions & -.949 & .559 & -.180 & -1.698 & .092 \\
\hline Deductions & .065 & .299 & .026 & .216 & .830 \\
\hline Interpretations & -1.150 & .814 & -.156 & -1.412 & .161 \\
\hline Argumentation & -.122 & .316 & -.041 & -.387 & .700 \\
\hline
\end{tabular}

a. Dependent Variable: Learning Beliefs

As it is evident in the table of coefficients (Table 8), none of the independent variables, i.e. inference $(\mathrm{t}=-.1 .45, \mathrm{p}=.14>.05)$, assumption $(\mathrm{t}=-1.69, \mathrm{p}=09>.05)$, deduction $(\mathrm{t}=.21, \mathrm{p}=83>.05)$, interpretation $(\mathrm{t}=-1.41, \mathrm{p}=16>.05)$, and argumentation $(\mathrm{t}=-$ $.38, \mathrm{p}=70>.05$ ), have significant contributions of $20 \%, 18 \%, 2 \%, 15 \%$, and $4 \%$, respectively. This means that when they are regarded together as a whole, i.e. critical thinking, they can jointly predict teachers' beliefs on language learning significantly, but when they are considered individually, this is not the case. In response to the second part of the research question, collinearity statistics also confirmed the lack of multicollinearity regarding the variables in the present phase of the study. In other words, the two values of Tolerance and VIF (Variance Inflation Factor) yielded satisfactory indices regarding the independent components. Table 9 shows the extent of these two values. 
Table 9

Collinearity Statistics

\begin{tabular}{lllcc}
\hline & & Model & Tolerance & VIF \\
\hline \multirow{2}{*}{1} & Inference & Assumption & .319 & 3.131 \\
\cline { 2 - 4 } & Deduction & .538 & 1.858 \\
\hline & Interpretation & .414 & 2.415 \\
\hline & Argumentation & .499 & 2.002 \\
\hline
\end{tabular}

a. Dependent Variables: Aptitude, Nature, Mot/Exp., Difficulty, Learn/Comm.

Table 9 proves that the five independent variables in this phase of the present study are not highly correlated with the five dependent ones due to the appropriate extent of Tolerance and VIF values related to all independent variables; i.e. inference: Tolerance $=.31>.10$, and VIF $=3.13<10$; assumption: Tolerance $=.53>.10$, and VIF $=1.85<$ 10; deduction: Tolerance $=.41>.10$, and VIF $=2.41<10$; interpretation: Tolerance $=$ $.49>.10$, and VIF $=2.00<10$; and argumentation: Tolerance $=.53>.10$, and VIF $=$ $1.86<10$. As it was mentioned before, according to Pallant (2016, p. 159), the "commonly used cut-off points for determining the presence of multicollinearity" include the "tolerance value of less than .10, or a VIF value of above 10," none of which are present in the current study. Consequently, this issue rejects the presence of multicollinearity in these five independent variables of the present phase. Residual statistics were also employed to decide on the existence of extreme scores that jererdize the normality of the distributions.

Table 10

Aptitude Residuals Statistics

\begin{tabular}{lccccc}
\hline & Minimum & Maximum & Mean & Std. Deviation & $\mathrm{N}$ \\
\hline Predicted Value & 32.7942 & 34.8501 & 33.9077 & .46461 & 130 \\
\hline Residual & -9.28742 & 9.58772 & .00000 & 3.70527 & 130 \\
\hline Std. Predicted Value & -2.397 & 2.028 & .000 & 1.000 & 130 \\
\hline Std. Residual & -2.457 & 2.537 & .000 & .980 & 130
\end{tabular}

Table 10, for instance, indicates that the maximum and minimum cases of aptitude standardized residuals are 2.53 and -2.45 , respectively. In other words, this table shows that all the 130 cases in this study were within the standardized residual value range, i.e. from -3.00 to 3.00 , devoid of any outliers; that is, the standardized residual values could mostly be regarded as close to the standardized predicted values, i.e. between -2.39 and 2.02. Also, the maximum and minimum cases of nature of language, Motivation/Expectation, difficulty and learning/ communication components were similarly within the standardized residual value range, i.e. from -3.00 to 3.00 , with a few number of outliers which are tolerable in regression; that is, the standardized residual values could somewhat be regarded as roughly close to the standardized predicted values.

Accordingly, ensuring that almost all the regression assumptions were checked, this study conducted a multivariate regression analysis so as to determine how well the five independent variables of inference, assumption, deduction, interpretation, and 
argumentation can predict the five dependent levels of language learning beliefs in particular, including language aptitude, nature of language, motivation and expectation, learning difficulty, and learning and communication. In this vein, Table 11 shows Model Summary of the respective data.

Table 11

Model Summary

\begin{tabular}{cllllll}
\hline \multicolumn{1}{c}{ Source } & Dependent Variable & Type III Sum of Squares & Mean Square & F & Sig. & R Squared \\
\hline \multirow{5}{*}{ Model } & Aptitude & 27.847 & 5.569 & .390 & .855 & .015 \\
\cline { 2 - 7 } & Nature & 164.479 & 32.896 & 2.728 & .023 & .099 \\
\cline { 2 - 7 } & Mot/Exp. & 695.962 & 139.192 & 8.998 & .000 & .266 \\
\cline { 2 - 7 } & Difficulty & 38.488 & 7.698 & .790 & .559 & .031 \\
\cline { 2 - 7 } & Learn/Comm. & 752.705 & 150.541 & 8.688 & .000 & .259 \\
\hline
\end{tabular}

As it can be seen from Table 11, the collective contribution of the five independent variables, i.e. inference, assumption, deduction, interpretation, and argumentation, altogether are only significant to three of the five dependent variables, i.e. $9 \%$ to language nature $\left(\mathrm{F}=2.72, \mathrm{p}<.05 ; \mathrm{R}^{2}=.09\right), 26 \%$ to motivation and expectation $(\mathrm{F}=$ $\left.8.99, \mathrm{p}<.05 ; \mathrm{R}^{2}=.26\right)$, and $25 \%$ to learning and communication $\left(\mathrm{F}=8.68, \mathrm{p}<.05 ; \mathrm{R}^{2}\right.$ $=.25$ ). However, this is not the case regarding language aptitude and learning difficulty. Table 12 illustrates the multivariate regression, showing the contribution of each independent variable.

Table 12

Multivariate Tests

\begin{tabular}{|c|c|c|c|c|c|}
\hline & Effect & Value & $\mathrm{F}$ & Sig. & Partial Eta Squared \\
\hline \multirow{4}{*}{ Inferences } & Pillai's Trace & .044 & 1.092 & .369 & .044 \\
\hline & Wilks' Lambda & .956 & 1.092 & .369 & .044 \\
\hline & Hotelling's Trace & .045 & 1.092 & .369 & .044 \\
\hline & Roy's Largest Root & .045 & 1.092 & .369 & .044 \\
\hline \multirow{4}{*}{ Assumptions } & Pillai's Trace & .106 & 2.832 & .019 & .106 \\
\hline & Wilks' Lambda & .894 & 2.832 & .019 & .106 \\
\hline & Hotelling's Trace & .118 & 2.832 & .019 & .106 \\
\hline & Roy's Largest Root & .118 & 2.832 & .019 & .106 \\
\hline \multirow{4}{*}{ Deductions } & Pillai's Trace & .016 & .390 & .855 & .016 \\
\hline & Wilks' Lambda & .984 & .390 & .855 & .016 \\
\hline & Hotelling's Trace & .016 & .390 & .855 & .016 \\
\hline & Roy's Largest Root & .016 & .390 & .855 & .016 \\
\hline \multirow{4}{*}{ Interpretations } & Pillai's Trace & .050 & 1.271 & .281 & .050 \\
\hline & Wilks' Lambda & .950 & 1.271 & .281 & .050 \\
\hline & Hotelling's Trace & .053 & 1.271 & .281 & .050 \\
\hline & Roy's Largest Root & .053 & 1.271 & .281 & .050 \\
\hline \multirow{4}{*}{ Arguments } & Pillai's Trace & .064 & 1.647 & .153 & .064 \\
\hline & Wilks' Lambda & .936 & 1.647 & .153 & .064 \\
\hline & Hotelling's Trace & .069 & 1.647 & .153 & .064 \\
\hline & Roy's Largest Root & .069 & 1.647 & .153 & .064 \\
\hline
\end{tabular}

As Table 12 shows, the independent variable of assumption is the only significant predictor in general, i.e. $\mathrm{F}=2.83, \mathrm{p}<.05$. In fact, assumption has a moderate 
contribution with the effect size of .10 , which is greater than .06 and less than .14 , interpreted as a moderate effect (Cohen, 1988, as cited in Yamini \& Rahimi, 2007, p. $81)$; i.e. $10 \%$ of the variances in the dependent variables on the whole is explained by the variance in assumption. However, as it can be seen from the table above, inference, deduction, interpretation, and argumentation are not significant predictors in general; although $4 \%, 1 \%, 5 \%$, and $6 \%$ of the whole variance seems to be explained by inference, deduction, interpretation, and argumentation, their contributions are not meaningful. Table 13 illuminates the tests of between-subjects effects, showing the contribution of each independent variable to each of the dependent ones.

Table 13

Tests of Between-Subjects Effects

\begin{tabular}{|c|c|c|c|c|c|c|}
\hline Source & Dependent Variable & Type III Sum of Squares & Mean Square & $\mathrm{F}$ & Sig. & $\begin{array}{l}\text { Partial Eta } \\
\text { Squared }\end{array}$ \\
\hline \multirow{5}{*}{ Inference } & Aptitude & .873 & .873 & .061 & .805 & .000 \\
\hline & Nature & 18.983 & 18.983 & 1.574 & .212 & .013 \\
\hline & Mot/Exp. & 36.809 & 36.809 & 2.379 & .125 & .019 \\
\hline & Difficulty & 3.390 & 3.390 & .348 & .556 & .003 \\
\hline & Learn/Comm. & 21.313 & 21.313 & 1.230 & .270 & .010 \\
\hline \multirow{5}{*}{ Assumption } & Aptitude & .042 & .042 & .003 & .957 & .000 \\
\hline & Nature & 2.265 & 2.265 & .188 & .665 & .002 \\
\hline & Mot/Exp. & 54.988 & 54.988 & 3.554 & .062 & .028 \\
\hline & Difficulty & 2.349 & 2.349 & .241 & .624 & .002 \\
\hline & Learn/Comm. & 127.835 & 127.835 & 7.378 & .008 & .056 \\
\hline \multirow{5}{*}{ Deduction } & Aptitude & 17.939 & 17.939 & 1.256 & .265 & .010 \\
\hline & Nature & .695 & .695 & .058 & .811 & .000 \\
\hline & Mot/Exp. & .447 & .447 & .029 & .865 & .000 \\
\hline & Difficulty & 2.712 & 2.712 & .278 & .599 & .002 \\
\hline & Learn/Comm. & .598 & .598 & .035 & .853 & .000 \\
\hline \multirow{5}{*}{ Interpretation } & Aptitude & 10.368 & 10.368 & .726 & .396 & .006 \\
\hline & Nature & 3.272 & 3.272 & .271 & .603 & .002 \\
\hline & Mot/Exp. & 53.396 & 53.396 & 3.452 & .066 & .027 \\
\hline & Difficulty & 33.330 & 33.330 & 3.422 & .067 & .027 \\
\hline & Learn/Comm. & 20.407 & 20.407 & 1.178 & .280 & .009 \\
\hline \multirow{5}{*}{ Argumentation } & Aptitude & 2.360 & 2.360 & .165 & .685 & .001 \\
\hline & Nature & 36.493 & 36.493 & 3.026 & .084 & .024 \\
\hline & Mot/Exp. & 1.301 & 1.301 & .084 & .772 & .001 \\
\hline & Difficulty & 10.619 & 10.619 & 1.090 & .298 & .009 \\
\hline & Learn/Comm. & 1.589 & 1.589 & .092 & .763 & .001 \\
\hline
\end{tabular}

As Table 13 reveals, only the contribution of assumption is significant merely to one of the dependent variables, i.e. learning/communication $(F=7.37, p<.05)$, with the small effect size of .05. In other words, just $5 \%$ of the variance in learning and communication is significantly explained by assumption. However, the table reveals that the variance of none of the dependent variables is significantly explained by the rest of the independent ones. 


\section{DISCUSSION}

The independent variable of assumption is the only significant predictor in general. In fact, assumption has a moderate contribution with the effect size of .10, which is greater than .06 and less than .14, interpreted as a moderate effect (Cohen, 1988, as cited in Yamini \& Rahimi, 2007, p. 81); i.e. $10 \%$ of the variances in the dependent variables on the whole is explained by the variance in assumption. However, it was realized that inference, deduction, interpretation, and argumentation are not significant predictors in general; although $4 \%, 1 \%, 5 \%$, and $6 \%$ of the whole variance seems to be explained by inference, deduction, interpretation, and argumentation, their contributions are not meaningful. The contribution of assumption was found to be significant merely to one of the dependent variables, i.e. learning/communication $(\mathrm{F}=7.37, \mathrm{p}<.05)$, with the small effect size of .05. In other words, just $5 \%$ of the variance in learning and communication is significantly explained by assumption. However, the table reveals that the variance of none of the dependent variables is significantly explained by the rest of the independent ones.

Based on the results, the contribution of critical thinking was significant only to two of the sub-components of teachers' beliefs, i.e. motivation/expectation $(\mathrm{F}=15.83, \mathrm{p}<.05)$ and learning/communication ( $\mathrm{F}(5,124) 8.35, \mathrm{p}<.05)$, with the moderate effect sizes of .11 and .06 , respectively. In other words, $11 \%$ of the variance in motivation and expectation, and $6 \%$ of the variance in learning and communication are significantly explained by critical thinking. This issue can be in line with most researchers' views on critical thinking as including both skills, or abilities, and dispositions. The disposition to think critically has been defined as the "consistent internal motivation to engage problems and make decisions by using critical thinking" (Facione, 2000, p. 65). Thus, motivation is viewed as a necessary precondition for critical thinking skills and abilities.

Similarly, Halonen (1995) notes that a person's propensity, or disposition towards higher-order thinking is related to their motivation. He argues that effort and persistence are two of the principal dispositions that support critical thinking, and Paul (1992, p. 13) maintains that perseverance is one of the "traits of mind" that renders someone as a critical thinker. Thus, motivation appears to be a supporting condition for critical thinking in that unmotivated individuals are unlikely to exhibit critical thinking. On the other hand, some motivation research has suggested that the causal link goes the other way. In particular, some motivation research suggests that difficult or challenging tasks, particularly those emphasizing higher-order thinking skills, may be more motivating than easy tasks that can be solved through the rote application of a predetermined algorithm (Turner, 1995).

On the other hand, critical thinking and learning/communication are interrelated. If communication is defined as a meaningful exchange of information, thoughts and feelings between two living creatures, critical thinking is the engine that provides this meaning. Communication starts with a thought, a feeling and an emotion. The mind builds on this thought before putting it out to the receiver. Critical thinking, quite simply, is the tool to coherently build our thoughts. Effective communication starts with 
a clear thought process. Critical thinking breeds clarity of thought (Vora, 2014). A constant pursuit of critical thinking equips teachers think rationally, provide sound reasoning and develop a coherent argument. When teachers think critically and communicate clearly, they are also able to eliminate ambiguity in educational communication.

\section{CONCLUSION}

One conclusion is that the critical thinking pedagogy can be an effective pedagogy for involving learners in classroom dialogue that creates learning and thinking opportunities. Teachers need a solid understanding of the critical thinking, and the value it has for themselves and their students. Teachers must learn to think critically and model and practice the techniques consistently with students. Teachers who take the time to learn new methods in teaching despite the challenges perceive themselves as successful. Support and continued professional development for current and future teachers in the critical thinking is needed. Teachers need to model critical thinking and practice it, using flexibility in their approach. Students need to use thinking skills in a variety of ways so they can then transfer the learned skill to other situations (Beyer, 1987). Motivating students is an ongoing challenge in the classroom, but the critical thinking is more student driven, student friendly, and can make a difference in the lives of students, their families and their communities. It is a step by step process, for teachers and students, creating and practicing more and more classroom lessons, assessments, and experiences in problem-solving manners, until the process becomes systematic to the way teachers teach. Critical thinking empower students and teachers. It behoves those preparing new teachers and providing in-service for practicing teachers to take the responsibility to provide training, resources, and support for teachers and model and practice critical thinking.

Based on the results of this study, it can be suggested that critical thinking be incorporated into teacher training and short-term in-service programs, especially for EFL teachers. These programs can help EFL teachers critically develop their ability in dealing with difficult and stressful situations and problems. These programs can help teachers decrease their level of critical thinking in their work environment and improve their success and motivation, which in turn help them to remain longer in their profession and be more effective in the classroom. This will certainly affect students' achievement and increase their learning. 


\section{REFERENCES}

Allen, G. D., Rubenfeld, M. G., \& Scheffer, B. K. (2004). Reliability of assessment of critical thinking. Journal of Professional Nursing, 20(1), 15-22.

Bernat, E. (2004). Investigating Vietnamese ESL learners' beliefs about language learning. EA Journal, 21(2), 40-54.

Chamot, A. (1995). Creating a community of thinkers in the ESL/EFL classroom. TESOL Matters, 5 (5), 1-16.

Dörnyei, Z. (2005). The psychology of the language learner.

Elder, L., \& Paul, R. (1997, Winter). Critical thinking: Crucial distinctions for questioning. Journal of Developmental Education 21(2), 34-57.

Facione, P. A. (2000). The disposition toward critical thinking: Its character, measurement, and relation to critical thinking skill. Informal Logic, 20(1), 61-84.

Fahim, M., \& Ahmadi, H. (2012). Critical thinking, content schemata, and EFL readers' comprehension and recall. Journal of Comparative Literature \& Culture, 1(1), 23-28.

Fahim, M., Barjesteh, H., \& Vaseghi, R. (2012). Effects of critical thinking strategy training male/female EFL learners' reading comprehension. English Language Teaching, 5(10), 140-145.

Halonen, J. S. (1995). Demystifying critical thinking. Teaching of psychology, 22(1), 75-81.

Horwitz, E. K. (1985). Surveying student beliefs about language learning and teaching in the foreign language methods course. Foreign Language Annals, 18(4), 333-340.

Horwitz, E.K. (1987). Surveying student beliefs about language teaming. In A.L. Wenden \& J. Robin (Eds.), Learner strategies in language learning (pp. 119-132). London: Prentice Hall.

Horwitz, E.K. (1988). The beliefs about language learning of beginning foreign language students. Modern Language Journal, 72(3), 283-294.

Kern, G. (1995). Students' and Teachers' Beliefs about Language Learning'. Foreign Language Annals 28(7), 71-92.

Klimoviene, G., Urboneine, J., \& Barzdziukiene, R. (2006). Developing critical thinking through cooperative learning. Retrieved from http://www.kalbos.It/zurnalai/09_numeris/11.pdf

Liaw, S. S., Huang, H. M., \& Chen, G. D. (2007). Surveying instructor and learner attitudes toward e-learning. Computers \& Education, 49(4), 1066-1080.

Lipman, M. (1988). Critical thinking — what can it be? Educational Leadership, 46(1), $38-43$. 
Mayer, R. E., \& Goodchild, F. (1990). The critical thinker. Santa Barbara, University of California, Wm. C.

Nosratinia, M., \& Zaker, A. (2013). Autonomous learning and critical thinking: Inspecting the association among EFL learners. In First National Conference on Teaching English, Literature, and Translation, Shiraz University, Shiraz, Iran. Retrieved from http://www. civilica. com/Paper-TELT01-TELT01_226. html.

Pallant, J. (2016). SPSS survival manual: a step by step guide to data analysis using IBM SPSS, 6th edn.

Paul, R., \& Elder, L. (2007). Critical thinking: The art of Socratic questioning. Journal of Developmental Education, 31(1), 36.

Paul, R. (1992). Critical thinking: What, why, and how. New directions for community colleges, 1992(77), 3-24.

Peacock, M. (1999). Beliefs about Language Learning and their Relationship to Proficiency. International Journal of Applied Linguistics, 9(2), 247-65.

Riley, P. A. (2009). Shifts in beliefs about second language learning. RELC Journal, 40(1), 102-124.

Sakui, K., \& Gaies, S. J. (1999). Investigating Japanese learners' beliefs about language learning. System, 27(4), 473-492.

Schafersman, S. D. (1998). Critical thinking and its relation to science and humanism. Retrieved November, 28, 2011.

Scriven, M. \& Paul, R. (2012) Defining Critical Thinking, Foundation for Critical Thinking. Available at: http://www.criticalthinking.org/aboutCT/definingCT.cfm

Shirkhani, S., \& Fahim, M. (2011). Enhancing critical thinking in foreign language learners. Procedia-Social and Behavioral Sciences, 29, 111-115.

Talebinejad, M. R., \& Matou, Z. (2012). Teacher-Student Interaction in EFL Reading Comprehension Contexts at University Level. SAGE Open, 2(4), 2158244012459335.

Tanaka, K., \& Ellis, R. (2003). Study abroad, language proficiency, and learner beliefs about language learning. JALT journal, 25(1), 63-85.

Tarvin, W., \& Al-Arishi, A. (1991). Rethinking communicative language teaching: Reflection and the EFL classroom. TESOL Quarterly, 25 (1), 9-27.

Turner, J. C. (1995). The influence of classroom contexts on young children's motivation for literacy. Reading Research Quarterly, 303), 410-441.

Vdovina, E., \& Gaibisso, L. (2013). Developing critical thinking in the English language classroom: A lesson plan. ELTA Journal, 1(1), 54-68. 
Vora, N. (2014). Between global citizenship and Qatarization: negotiating Qatar's new knowledge economy within American branch campuses. Ethnic and Racial Studies, 37(12), 2243-2260.

Wenden, A. (1999). An introduction to metacognitive knowledge and beliefs in language learning: Beyond the basics [Special Issue]. System, 27, 435-441.

Yamini, M., \& Rahimi, M. (2007). A guide to statistics and SPSS for research in TEFL, linguistics and related disciplines. Shiraz: Koushamher. 